\title{
Correction to: Low conductivity on electrical properties tomography demonstrates unique tumor habitats indicating progression in glioblastoma
}

\author{
Ji Eun Park ${ }^{1} \cdot$ Ho Sung Kim ${ }^{1}$ (D) NakYoung Kim ${ }^{2}$ - Young-Hoon $\mathrm{Kim}^{3}$ • Jeong Hoon Kim ${ }^{3}$ • Eunju Kim ${ }^{4}$. \\ Jinwoo Hwang ${ }^{4}$. Ulrich Katscher ${ }^{5}$
}

Published online: 7 June 2021

(C) European Society of Radiology 2021

\section{Correction to: European Radiology.}

https://doi.org/10.1007/s00330-021-07976-w

The original version of this article, published on 20 April 2021, unfortunately contained a mistake. The following correction has therefore been made in the original: The spelling of Ulrich Katscher's name was incorrect. The corrected author list is given above. The original article has been corrected.

Publisher's note Springer Nature remains neutral with regard to jurisdictional claims in published maps and institutional affiliations.

The online version of the original article can be found at https://doi.org/ 10.1007/s00330-021-07976-w

Ho Sung Kim

radhskim@gmail.com

1 Department of Radiology and Research Institute of Radiology,

University of Ulsan College of Medicine, Asan Medical Center, 43

Olympic-ro 88, Songpa-Gu, Seoul 05505, South Korea

2 JAPEX LLC, Seoul, South Korea

3 Deparment of Neurosurgery, University of Ulsan College of Medicine, Asan Medical Center, Seoul 05505, South Korea

4 Philips Healthcare, Seoul, South Korea

5 Department of Tomographic Imaging, Philips Research Laboratories, Hamburg, Germany 